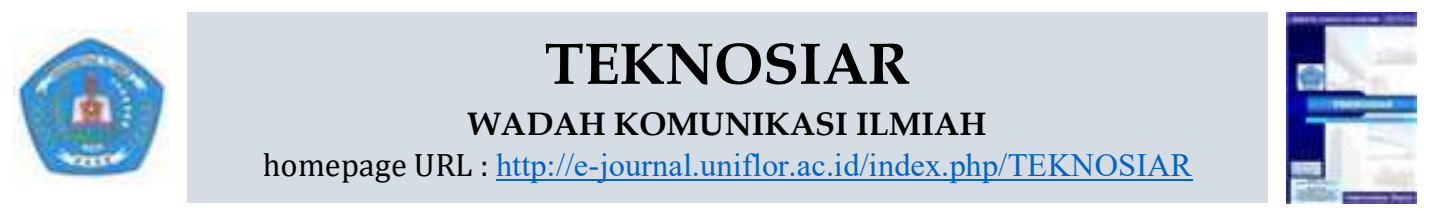

\title{
Kajian Pemanfaatan Air Hujan Sebagai Pemenuhan Kebutuhan Air Bersih Di Pulau Ende
}

\author{
*Valentinus Tan ${ }^{1}$, Mikael Wora ${ }^{2}$ \\ ${ }^{1,2}$ Program Studi Teknik Sipil, Fakultas Teknik, Universitas Flores, Ende \\ *) Correspondence e-mail: tanvalentinus96@gmail.com
}

Received:27-03-2021 Revised:05-04-2021.Accepted 20-04-2021

\begin{abstract}
ABSTRAC
The main objective of this research is to determine the quantitative hydrology of rainwater use on an individual scale to meet the clean water needs of residents in Pulau Ende District. The method used is to use a rain cycle program 2 which is simulated using the input data of the roof area community ( $m 2)$, water needs based on the number of family members (m3/day) and daily rainfall data in one year (mm/year). The main result of this study is to determine the quantitative hydrology of rainwater to meet the needs of clean water for rural communities in Pulau Ende sub-district, namely the percentage of the amount of water whose water is met for 3 tanks at least 50\% based on water needs in 2016 to 2020.
\end{abstract}

Keywords: Rainwater harvesting; Quantitative hydrology; Rain cycle 2; Small island

\begin{abstract}
Tujuan utama penelitian ini adalah untuk menetapkan hidrologi kuantitatif penggunaan air hujan skala individu untuk memenuhi Kebutuhan air bersih penduduk di Kecamatan Pulau Ende. Metode yang digunakan adalah dengan menggunakan program siklus hujan 2 yang disimulasikan dengan menggunakan data input masyarakat luas atap (m2), kebutuhan air berdasarkan jumlah anggota keluarga (m3/hari) dan data curah hujan harian dalam satu tahun (mm/tahun). Hasil utama dari penelitian ini adalah untuk mengetahui kuantitatif hidrologi air hujan untukmemenuhi kebutuhan air bersih bagi masyarakat desa di Kecamatan Pulau Ende, yaitu persentase jumlah air yang airnya terpenuhi untuk 3 tangki minimal 50\% berdasarkan kebutuhan air pada tahun 2016 sampai dengan tahun 2020.
\end{abstract}

Keywords: Pemanenan air hujan; Hidrologi kuantitatif; siklus hujan 2; Pulau kecil

\section{PENDAHULUAN}

Pulau - Pulau Kecil di Indonesia mencapai 13.000 buah pulau kecil dan 17.000 buah pulau besar, ditinjau dari sisi biofisik, geografi, penduduk, budaya dan daya lingkungannya, sangat unik, (Hermawan,2014). Air tanah di pulau-pulau kecil merupakan lensa yang mengapung di atas air payau atau air asin dengan ketebalan yang sangat tergantung pada imbuhan (recharge) dan rentan terhadap penyusutan air laut. Air tanah di pulau-pulau kecil seluruhnya berasal dari air hujan dengan siklus pendek untuk sampai ke laut, sehingga tidak sempat dimanfaatkan. Pemerintah Kabupaten Ende telah menetapkan Perda Nomor 3 tahun 2009 tentang RPJPD Tahun 2005-2025. Dokumen ini memuat visi masyarakat Kabupaten Ende, yang wajib diemban oleh Bupati dan Wakil Bupati Ende, sesuai periode rencana jangka menengah yaitu Tahap I ( RPJMD 2004 -

TEKNOSIAR Volume 15, No.01, April 2021

p-ISSN 1907-5197 (versi cetak) e-ISSN 2721-2270 (versi online) 
2009), Tahap II ( RPJMD 2009 - 2014), Tahap III ( RPJMD 2014 - 2019), dan Tahap IV ( RPJMD 2019 - 2025). Saat ini Kabupaten Ende memasuki tahap IV pelaksanaan RPJP atau RPJMD Tahun 2019- 2025, RPJMD Kabupaten Ende dirumuskan berdasarkan identifikasi permasalahan pokok dan mendesak yang dihadapi masyarakat Kabupaten Ende dengan menempatkan aspek manusia sebagai Kordinat melalui Prioritas Pembangunan bidang Pendidikan, Kesehatan, dan Prioritas pembangunan Ekonomi ketiga prioritas utama tersebut di atas, didukung prioritas penunjang yaitu Infrastruktur dan lingkungan hidup, dan Penegakan Hukum dan Ketertiban. Pembangunan infrastruktur dan lingkungan difokuskan dalam rangka pemenuhan kebutuhan dasar masyarakat salah satunya tentang penyediaan air bersih untuk Domestik karena sebagian Kecamatan dan Desa yang masih mengandalkan air hujan sebagai pemenuhan kebutuhan masyarakat.

Pemerintah menyarankan dengan mendasarkan pada meteorologi dan karakteristik geografis pemanenan air hujan, dimana curah hujan tahunan di Indonesia mencapai $2263 \mathrm{~mm}$ yang cenderung terdistribusi secara merata sepanjang tahun tanpa ada perbedaan yang mencolok antara musim hujan dan musim kemarau (Song et al., 2009). Oleh karena itu pemanenan air hujan di Indonesia perlu ditindaklanjuti sebagai salah satu upaya pengelolaan sumber daya air yang berkelanjutan. Air hujan merupakan sumber air yang berkualitas tinggi dimana tersedia setiap musim hujan dan berpotensi untuk mengurangi tekanan terhadap pemakaian sumber air bersih (fresh water sources). Penampungan air hujan yang berasal dari atap rumah biasanya merupakan alternatif air terbersih yang dapat digunakan sebagai sumber air bersih dan hanya membutuhkan pengolahan yang sederhana sebelum air digunakan.

Pulau Ende merupakan sebuah Pulau kecil dan merupakan sebuah kecamatan dalam wilayah administrasi Kabupaten Ende, Provinsi Nusa Tenggara Timur, walaupun dikelilingi lautan, air menjadi barang mahal dan langkah sampai di pulau ini, karena nyaris tidak ada air tawar, Sebagian besar sumur di pulau ini menghasilkan air payau. Dalam penanganan ini maka Pada tahun 2012 Melalui kantor khusus Presiden Republik Indonesia untuk Millenium Development Goals, 4 orang anak muda Pencerah Nusantara diterjunkan ke Pulau ini guna berfokus pada masalah masalah kesehatan masyarakat salah satunya adalah penanganan air bersih (Hendrawan, 2014). Pada tahun 2015 Proyek Sea Water Reverse Osmosis (SWRO) atau alat penyulingan air laut menjadi air tawar di kerjakan di pulau Ende, dengan nama proyek "Proyek Penyulingan Air Laut"' dengan total dana Rp 14 M namu tetap saja tidak menyelesaikan masalah pelik tersebut, karena alat yang dikerjakan tidak berfungsi (Ika).

Penanganan air bersih memang sangat menarik karena Air bersih yang tersedia di Pulau ini adalah air tanah (Sumur) yang tidak bisa digunakan untuk dikonsumsi, biasanya masyarakat mengkonsumsi air yang dibeli dari kota Ende, sedangkan untuk kebutuhan sehari-hari lainnya masyarakat membeli air dari penjual keliling menggunakan mobil tangki namun air itupun masih payau, Jika digunakan untuk minum terasa asin dan untuk mandi, maka akan terasa lengket di badan.

Pulau Ende didaulat sebagai pulau dengan ribuan Penampung Air Hujan (PAH), karena di musim hujan, masyarakat menampung air menggunakan Bak Penampung air hujan (PAH), dan dengan menggunakan alat seadanya seperti ember dan tandon air. Namun hanya cukup untuk memenuhi kebutuhan dalam jangka waktu yang pendek.

Merujuk dari pemanfaaatan teknologi rain water harvesting di berbagai Negara, maka atap dapat menjadi salah satu upaya alternatif yang dapat dijadikan sebagai sistem penyediaan air bersih di Kecamatan Pulau Ende. Selama ini air hujan yang jatuh di atas atap tidak ditampung dan hanya dibiarkan meresap atau masuk ke saluran drainase saja, sehingga upaya konservasi air melalui penampungan air hujan dirasa perlu untuk dilakukan.

TEKNOSIAR Volume 15, No.01, April 2021 


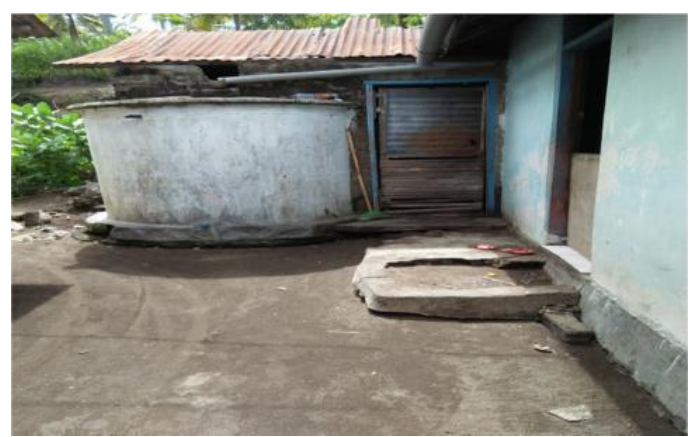

Gambar 1. Kondisi Penampungan Air hujan Di Pulau Ende

\section{A. Komponen Sistem Pemanenan Air}

\section{Hujan}

Pemanenan Air Hujan adalah teknik pengumpulan dan penampungan air hujan ke dalam tangki atau waduk. Air hujan dialirkan melalui pipa penghubung yang dipasang di atap- atap rumah menuju tempat penampungan di bawahanya. Lalu air akan dialirkan ke bak pengambilan air. Sistem pemanenan air hujan biasanya terdiri dari area tangkapan, saluran pengumpulan atau pipa yang mengalirkan air hujan yang turun di atap tangki penyimpanan (cistern or tanks). Saluran pengumpulan atau pipa mempunyai ukuran, kemiringan dan dipasang sedemikian rupa agar kuantitas air hujan dapat tertampung semaksimal mungkin (Abdullaetal, 2009). Ukuran saluran penampung bergantung pada luas area tangkapan hujan, biasanya diameter saluran penampung berukuran 20-50 cm (Abdullaet al., 2009). Filter dibutuhkan untuk menyaring sampah (daun, plastik, dan ranting) yang ikut bersama air hujan dalam saluran penampung sehingga kualitas air hujan terjaga. Dalam kondisi tertentu, filter harus bisa dilepas dengan mudah dan dibersihkan dari sampah.

Tangki (Cistern or tank) alami (kolam atau dam) dan tangki buatan merupakan tempat untuk meyimpan air hujan. Tangki penyimpanan air hujan dapat berupa tangki tanah atau dibawah tanah (ground tank). Apabila kualitas air hujan merupakan prioritas, saluran pembuangan air hujan yang tertampung pada menit-menit awal harus dibuang. Tujuan fasilitas ini adalah untuk meminimalkan polutan yang ikut bersama air hujan.

Sistem pemanenan air hujan yang digunakan dalam kajian ini adalah sistem Sistem pemanenan air hujan sederhana yaitu atap sebagai daerah tangkapan air, pipa sebagai sistem pengaliran dan tangki sebagai sistem penyimpanan Performa system Pemanenan air hujan sangat ditentukan oleh kapasitas tangki penyimpanan. Kapasitas tangki penyimpanan merupakan komponen yang penting karena akan menentukan performa sistem secara keseluruhan dan biaya yang dibutuhkan. Performa tangki tersebut dipengaruhi oleh karakteristik daerah tangkapan air, potensi curah hujan dan kebutuhan air yang diperlukan.

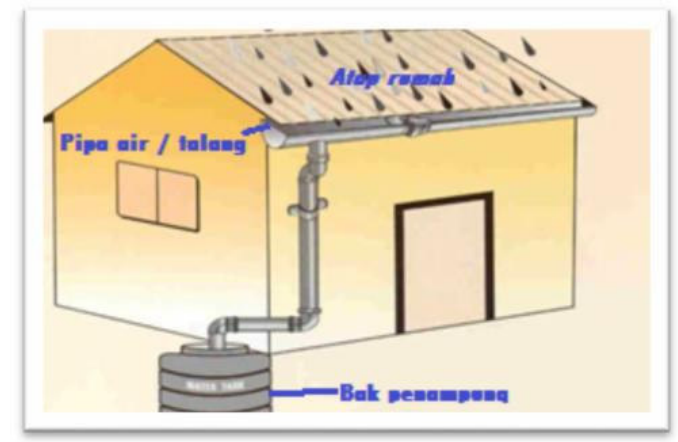

Gambar 2. Tiga Komponen Dasar Pemanenan Air Hujan : Atap rumah (Area Tangkapan), Pipa Air/Talang (Sistem Pengiriman), dan Bak Penampung/Tandon air (Penampungan).

TEKNOSIAR Volume 15, No.01, April 2021

p-ISSN 1907-5197 (versi cetak) e-ISSN 2721-2270 (versi online) 


\section{B. Tipe Sistem Pemanenan Air Hujan}

Beberapa sistem pemanenan air hujan yang dapat diterapkan Menurut program Lingkungan perserikatan bangsa-bangsa Un Environment Programme (UNEP, 2001), adalah sebagai berikut :

1) Sistem atap (roof system)

Sebuah system pemanenan air hujan terdiri dari tiga elemen dasar yaitu : area koleksi, Sistem alat angkut, dan fasilitas penyimpan. Tempat penampungan dalam banyak kasus adalah atap rumah atau bangunan. Luas efektif atap dan bahan yang digunakan dalam membangun atap mempengaruhi efisiensi pengumpul dan kualitas air.

Sebuah system pengangkutan biasanya terdiri dari talang atau pipa yang memberikan air hujan yang jatuh diatas atap untuk tangki air atau kapal penyimpan lain. Baik drainpipes dan permukaan atap harus terbuat dari bahan kimia lembam seperti kayu, plastic, alumunium, atau fiberglass, untuk menghindari efek buruk pada kualitas air. Air pada akhirnya disimpan dalam tangki penyimpan atau tadah, yang juga harus terbuat dari bahan inert, beton bertulang, fiber glass, atau stainless steel adalah bahan yang cocok. Tangki penyimpanan bisa dibangun sebagai bagian dari bangunan. Atau bisa juga agak jauh dari gedung. Untuk contoh system pemanenan air hujan dapat dilihat di bawah ini :
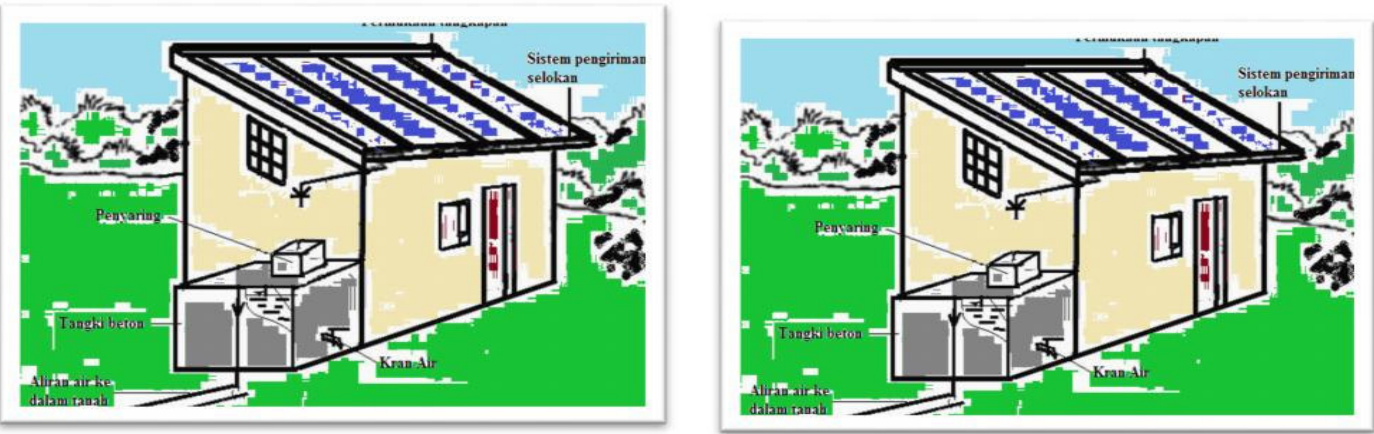

Gambar 3. Ilustrasi Sistem Pemanenan Air Hujan Menggunakan Atap

2) Sistem permukaan tanah (land catchment area)

Menggunakan permukaan tanah merupakan metode yang sangat sederhana untuk mengumpulkan air hujan. Dibandingkan dengan sistem atap, pemanenan air hujan dengan sistem ini lebih banyak mengumpulkan air hujan dari daerah tangkapan yang lebih luas. Air hujan yang terkumpul dengan sistem ini lebih cocok digunakan untuk pertanian, karena kualitas air yang rendah. Air dapat ditampung dalam embung atau danau kecil. Namun, ada kemungkinan sebagian air yang tertampung akan meresap kedalam tanah.

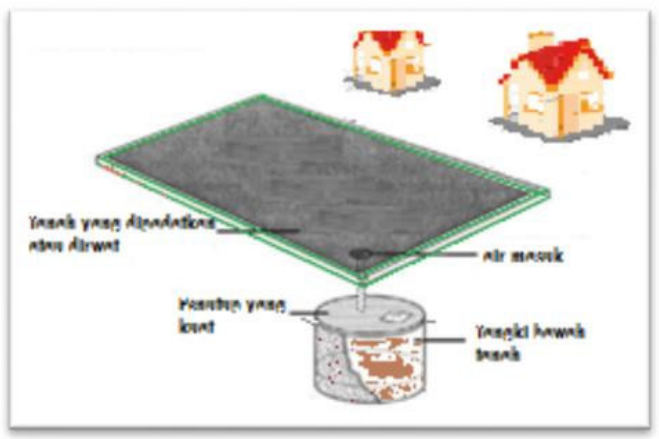

Gambar 4. Ilustrasi Pemanenan Air Hujan Menggunakan Permukaan Tanah

TEKNOSIAR Volume 15, No.01, April 2021

p-ISSN 1907-5197 (versi cetak) e-ISSN 2721-2270 (versi online) 


\section{METODE}

Pada prinsipnya proses pelaksanaan studi ini terbagi dalam tiga bagian yaitu pengumpulan data, pengolahan data hingga keluaran yang berupa hasil analisa. Data yang digunakan dalam Jurnal ini adalah data primer dan data sekunder. Adapun data primer yang digunakan dalam penelitian ini adalah data luas atap masyarakat $\left(\mathrm{m}^{2}\right)$ dan data jumlah orang dalam satu keluarga. Sedangkan untuk data sekunder yang digunakan adalah data curah hujan harian rata-rata dari data BPS Kabupaten Ende pada tahun 2010-2014. Pada penelitian ini menggunakan pemodelan siklus hujan 2 yang menggunakan data primer dan data sekunder tersebut, yang menghasilkan suatu persentase pemenuhan kebutuhan air dan jumlah tangki yang digunakan untuk skala individual di Kecamatan Pulau Ende Kabupaten Ende, Provinsi Nusa Tenggara timur.

\section{HASIL DAN PEMBAHASAN}

Simulasi Model siklus hujan 2 dengan data sampel luas atap $231 \mathrm{~m}^{2}$ dengan 7 anggota keluarga. Data curah hujan yang diambil dari data BPS Tahun 2010 sebesar 4560,17 mm/hari. Data Luas Atap Rumah seluas $231 \mathrm{~m}^{2}$, penetapan koefisien pengaliran (Run Off Coefficient) sebesar 0,75 dengan tipe Pitched Roof Tile.

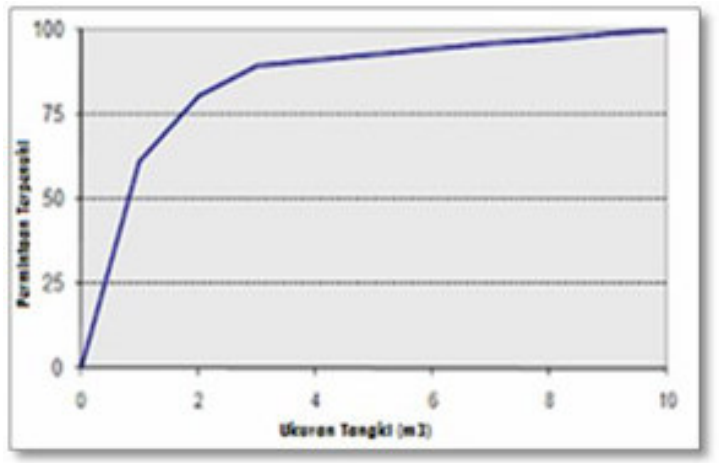

Gambar 5. Grafik Hubungan antara Jumlah Tangki dalam $\mathrm{m}^{3}$ terhadap kebutuhan air bersih Skala Individu dalam \%

Mempresentasikan hubungan antara jumlah tangki dalam $\mathrm{m}^{3}$ terhadap kebutuhan air bersih dalam $\%$ dengan mengasumsikan bahwa penggunaan tangki penampung yang lazim digunakan di masyarakat adalah tangki yang terbuat dari beton bertulang dengan kapasitas tamping 5000 liter atau $5 \mathrm{~m}^{3}$

Tabel 1. Hubungan Antara Kebutuhan Jumlah Tangki Terhadap Kontribusi Air Hujan Untuk Pemenuhan Kebutuhan Air Bersih Skala Individu Untuk Tahun 2016

\begin{tabular}{|c|c|c|}
\hline $\begin{array}{l}\text { Jumlah Tangki yang } \\
\text { Dibutuhkan (buah) }\end{array}$ & $\begin{array}{l}\text { Volume Tampungan Tangki } \\
\text { yang dibutuhkan }\left(\mathrm{m}^{3}\right)\end{array}$ & $\begin{array}{l}\text { Sumbangan Air Hujan Untuk } \\
\text { Kebutuhan Air Bersih (\%) }\end{array}$ \\
\hline 2 & 2 & 67,5 \\
\hline 3 & 3 & 82,6 \\
\hline 4 & 4 & 90,3 \\
\hline
\end{tabular}

Sumber : Hasil model siklus hujan 2

TEKNOSIAR Volume 15, No.01, April 2021

p-ISSN 1907-5197 (versi cetak) e-ISSN 2721-2270 (versi online) 
Tabel 2. Hubungan Antara Kebutuhan Jumlah Tangki Terhadap Kontribusi Air Hujan Untuk Pemenuhan Kebutuhan Air Bersih Skala Individu Untuk Tahun 2017

\begin{tabular}{|c|c|c|c|c|c|}
\hline $\begin{array}{l}\text { Jumlah Tangki yang } \\
\text { Dibutuhkan (buah) }\end{array}$ & \multicolumn{4}{l}{$\begin{array}{l}\text { Volume Tampungan Tangki } \\
\text { yang dibutuhkan }\left(\mathrm{m}^{3}\right)\end{array}$} & $\begin{array}{l}\text { Sumbangan Air Hujan Untuk Kebutuhan Air } \\
\text { Bersih (\%) }\end{array}$ \\
\hline & & 2017 & 2018 & 2019 & 2020 \\
\hline 2 & 2 & 57,5 & 55,3 & 66,2 & 46,5 \\
\hline 3 & 3 & 70,5 & 66,9 & 78,3 & 53,5 \\
\hline 4 & 4 & 78,8 & 74,7 & 85 & 58,6 \\
\hline
\end{tabular}

Sumber : Hasil model siklus hujan 2

Berdasarkan hasil Tabel 1, dan Tabel 2, maka dapat disusun grafik hubungan yang merepresentasikan antara jumlah tangki dalam $\mathrm{m}^{3}$ terhadap kebutuhan air bersih dalam \% dengan mengasumsikan bahwa menggunakan tangki penampung yang digunakan di masyarakat adalah 2, 3 dan 4 buah tangki yang terbuat dari fiber dengan kapasitas tampung 1000 liter atau $1 \mathrm{~m}^{3}$.

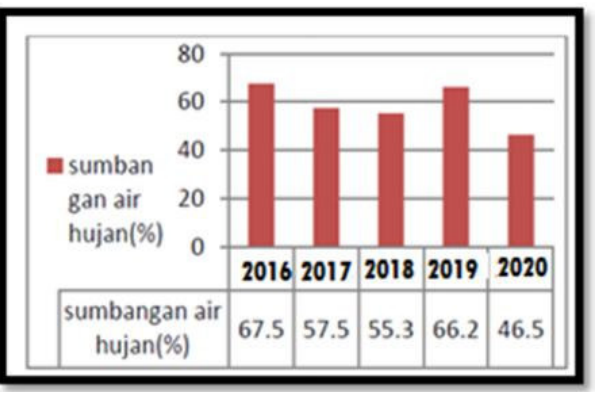

Gambar 6. Grafik Sumbangan Air Hujan (\%) Untuk Kebutuhan Pemenuhan Air Bersih menggunakan 2 Buah Tangki

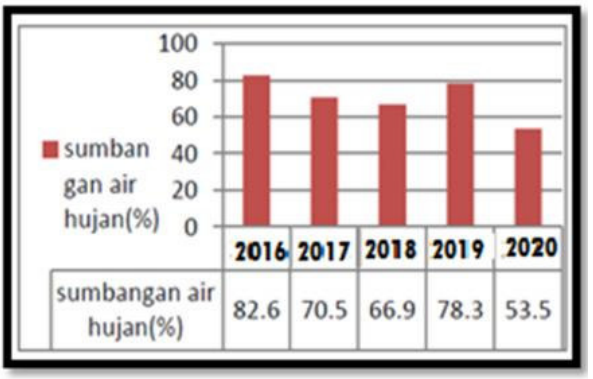

Gambar 7. Grafik Sumbangan Air Hujan (\%) Untuk Kebutuhan Pemenuhan Air Bersih menggunakan 3 Buah Tangki

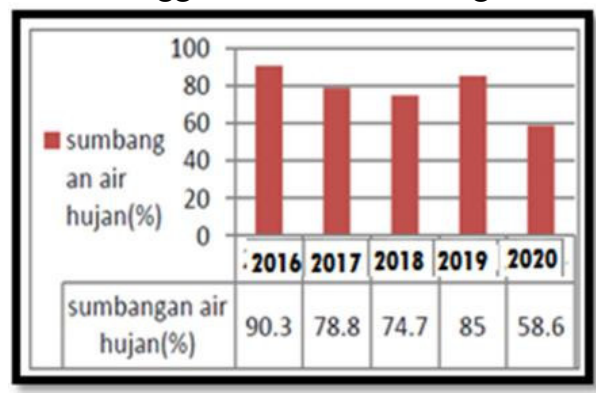

Gambar 8. Grafik Sumbangan Air Hujan (\%) Untuk Kebutuhan Pemenuhan Air Bersih menggunakan 4 Buah Tangki

TEKNOSIAR Volume 15, No.01, April 2021

p-ISSN 1907-5197 (versi cetak) e-ISSN 2721-2270 (versi online) 
Berdasarkan Gambar 6, Gambar 7 dan Gambar 8, maka perubahan parameter curah hujan khususnya data curah hujan 2020 memberikan pengaruh terhadap pemenuhan kebutuhan air bersih di Pulau Ende yang diklasifikasikan sebagai pulau kecil yang sangat rentan akan pemenuhan kebutuhan air bersih sepanjang tahun, yang dijelaskan dalam bentuk grafik pengaruh hubungan antara curah hujan dengan persentasi kebutuhan air yag terpenuhi dengan nilai $R$ yaitu 0,734 yang memiliki nilai korelasi kuat. Sedangkan untuk jumlah tangki yang dibutuhkan dalam memenuhi kebutuhan air bersih masyarakat Pulau Ende yaitu 3 tangki karena persentase jumlah tangki yang dibutuhkan masuk dalam $50 \%$ ke atas.

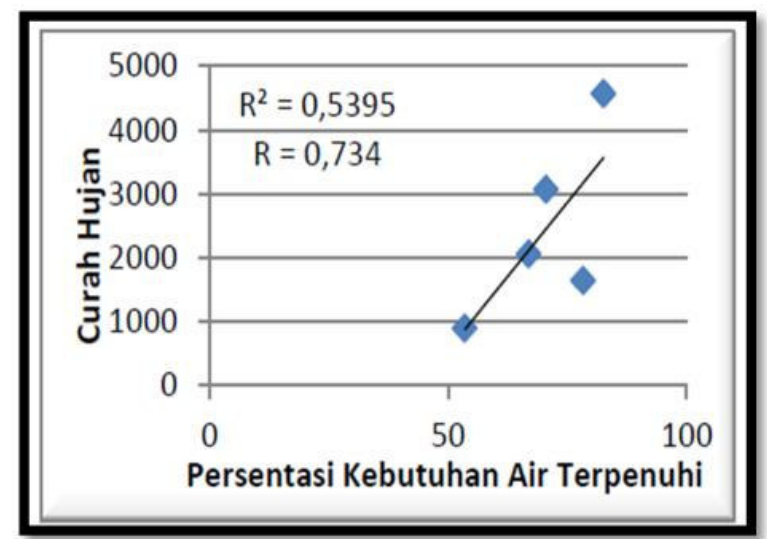

Gambar 9. Grafik Hubungan Antara Curah Hujan Harian Pada Tahun 2016-2020 dengan Persentase Kebutuhan Air yang Terpenuhi pada Luas Atap $231 \mathrm{~m} 2$ dengan 7 orang

Untuk langkah yang sama dilakukan juga pada sampel rumah dengan luas $231 \mathrm{~m} 2$ dengan 6 anggota keluarga, $204 \mathrm{~m} 2$ dengan 7 anggota kelurga dan $112 \mathrm{~m} 2$ dengan 6 anggota keluarga. Yang kemudian akan dijelaskan dalam bentuk tabel \% pemenuhan kebutuhan air dengan 3 buah tangki. Dan perbandingan masing-masing \% pemenuhan kebutuhan air pada luas atap dan jumlah anggota keluarga yang berbeda.

Tabel 3. Persentase Pemenuhan Kebutuhan Air Pada 3 Buah Tangki Penampungan Dengan Luas Atap Dan Jumlah Anggota Yang Berbeda

\begin{tabular}{|c|c|c|c|c|}
\hline \multirow{2}{*}{ Tahun } & \multicolumn{4}{|c|}{$\%$ Pemenuhan Kebutuhan Air } \\
\cline { 2 - 5 } & $\begin{array}{l}\text { 231 m2 dengan 7 } \\
\text { anggota keluarga }\end{array}$ & $\begin{array}{l}231 \mathrm{~m} 2 \text { dengan } 6 \\
\text { anggota keluarga } \\
\text { 204 m2 dengan 7 } \\
\text { anggota keluarga }\end{array}$ & $\begin{array}{l}\text { 112 m2 dengan 6 anggota } \\
\text { keluarga }\end{array}$ \\
\hline 2016 & $82,6 \%$ & $87,7 \%$ & $81,6 \%$ & $82,8 \%$ \\
\hline 2017 & $70,5 \%$ & $75,5 \%$ & $69,9 \%$ & $70,5 \%$ \\
\hline 2018 & $66,9 \%$ & $72,2 \%$ & $65,9 \%$ & $65,2 \%$ \\
\hline 2019 & $78,3 \%$ & $82,9 \%$ & $77,3 \%$ & $66,8 \%$ \\
\hline 2020 & $53,5 \%$ & $59,7 \%$ & $50,5 \%$ & $41,2 \%$ \\
\hline
\end{tabular}

Berdasarkan Tabel 3, dijelaskan bahwa dengan luas atap yang sama dan dengan jumlah anggota keluarga yang berbeda memberikan pengaruh terhadap hasil persentasi pemenuhan kebutuhan air. Dimana semakin banyak anggota keluarga maka semakin sedikit pemenuhan kebutuhan airnya.

TEKNOSIAR Volume 15, No.01, April 2021

p-ISSN 1907-5197 (versi cetak) e-ISSN 2721-2270 (versi online) 


\section{KESIMPULAN}

Berdasarkan hasil penelitian tersebut, maka dapat ditarik suatu sebagai berikut ini :

a. Parameter curah hujan memberikan pengaruh terhadap hidrologi kuantitatif pemanenan air hujan skala individual yang didapatkan dari hasil model siklus air hujan untuk memenuhi kebutuhan air di Pulau Ende Kabupaten Ende. Dimana semakin tinggi curah hujan maka semakin tinggi pemenuhan kebutuhan airnya.

b. Luas atap masyarakat yang digunakan sebagai area tangkapan hujan dan jumlah anggota keluarga memberikan pengaruh terhadap kapasitas air tampungan. Dimana semakin besar luas atap maka semakin besar pemenuhan kebutuhan airnya sedangkan jika semakin banyak jumlah anggota keluarga maka semakin sedikit pemenuhan kebutuhan airnya.

\section{DAFTAR USTAKA}

Abdulla, Fayez A., \& AW Al- Shareef.2009. Roof rainwater harvesting systems for household water supply in Jordan.Desalination.

Appan, A., 1999. A dual-mode system for harnessing roofwater for nonpotable uses. Urban Water 1 .

BPS Badan Pusat Statistic data Kabupaten Ende 2010-2014, Nusa Tenggara Timur.

Ghisi, Enedir., Davida, Fonseca T., \& Vinicius, Luis R. (2009). Rainwater harvesting in petrol stations in Brasilia: Potential for potable water saving and investment feasibility analysis. Resources, Conservation and Recycling.

google, Posted by: Reza Hendrawan // News and Features // February 23, 2014),

Hermawan. 2014. Pola Pengelolaan Penampung Air Hujan (PAH) Berbasis Modal Sosial; ( Studi Kasus Di Pulau Ende Dan Pulau Solor Provinsi Nusa Tenggara Timur ). Kementrian Pekerjaan Umum.

Kompas.com, Penulis : Kontributor Maumere, Nansianus Taris, Editor : Aprillia Ika.

Putra, Aditya Eka. 2015. Evaluasi Penampungan Air Hujan (Pah) Untuk Pemenuhan Kebutuhan Air Domestik Di Desa Giriharjo Kecamatan Panggang Kabupaten Gunung Kidul. Skripsi, Fakultas Geografi, Universitas Gaja Mada. Yogyakarta.

Song, Jaemin., Mooyoung, Han., Tschungil, Kim., \& Jee-eun Song. 2009. Rainwater Harvesting as a sustainable water supply option in Banda Aceh. Seoul National University.

Suprayogi Imam. (2015). Aplikasi Teknologi Rain Water Harvesting Sebagai Alternatip Pemenuhan Kebutuhan Air Bersih Pada Daerah Rawa di Provinsi Riau .Hasil Penelitian Desentralisasi Skema Unggulan Perguruan Tinggi LPPM Universitas Riau.

UNEP International Technology Centre.2001. Rainwater Harvesting. Murdoch University of Western Australia.

TEKNOSIAR Volume 15, No.01, April 2021

p-ISSN 1907-5197 (versi cetak) e-ISSN 2721-2270 (versi online) 